\title{
Perception on Use of Sanitary Napkins Among Students in Khammam Locality: a Survey
}

\author{
Pooja Arugula1 ${ }^{*}$, Suresh Kumar Paramasivam², Niharika Kanuri', Akhila Srirangam, Mounika \\ Vemuluri ${ }^{1}$
}

${ }^{1}$ Pharm D, Department of Pharmacy Practice, Browns College of Pharmacy, Khammam, Affilated To Kakatiya University, Telangana, INDIA.

${ }^{2}$ Professor, Department of Pharmaceutics, Browns College of Pharmacy, Khammam, Affilated To Kakatiya University, Telangana, INDIA.

\begin{abstract}
Background: We conducted a survey to analyze the student's perception on sanitary napkins in Khammam locality. Method: To carry out our studies we started our work on November 2016 and completed by April 2017 during which we provided each student (around 500 students of age group 11-20 and 21-30) with a printed copy comprising of various queries regarding sanitary napkins. Based on the obtained data we found that, in students of both the age groups majority of the students are rarely experiencing discomfort, rashes $(47.55 \%$ on average), majority of the students are not satisfied with the price $(59.25 \%$ on average), most of the students are not at all having any idea about the chemicals used in sanitary napkins (57.29\% on average), majority of students change their sanitary napkins at a time interval of $4-8 \mathrm{~h}(46.7 \%$ on average) and majority of students consider various factors like comfort, quality, price, size, package (37.75\% on average) while choosing a sanitary napkin. Conclusion: Finally, we found out that most of the students are not satisfied with the price of the sanitary napkins and even they are not aware of the chemicals that are being used in the manufacturing of the sanitary napkins.
\end{abstract}

Key words: Sanitary napkins, Survey, Perception, Students, Queries.

\section{INTRODUCTION}

Sanitary napkins should not only provide comfort and safety but must enhance woman's health and lifestyle. Looking at the level of technological advance, the 21 st century women may not restore back to the use of cloths even they are effective to lessen gynecological problems as compared to sanitary napkins because of the chemicals present in it. 1,2,3

\section{Key Criteria for Selection of Sanitary Pads}

Hygiene: Sanitary waste disposal has become an increasing problem in India as the plastic used in disposable sanitary napkins are not biodegradable.

Performance: Generally women also prefer sanitary napkins based on their absorptive capacity.
Comfort: Women also prefer comfort as they are used throughout the day during menstruation.

Convenience: It must be convenient to carry anywhere along with them.

Cost: The biggest barrier to use sanitary napkin is affordability. Only $12 \%$ of India's 355 million menstruating women use sanitary napkins (SNs). Over $88 \%$ of women restore to shocking alternatives like unsanitised cloth, ashes and husk sand.

Conditions evoked by using poor quality sanitary napkins

Vaginal inflammation, cervical inflammation and erosion, urinal pain, fatigue, genital herpes and genital warts, menstrual disorders.

Chemicals used in Sanitary Napkins
DOI: 10.5530/ijopp.10.2.27

Address for correspondence: Ms. Pooja Arugula, Department of Pharm-D, Browns College of Pharmacy, Ammapalem (V), Konijerla (M), Khammam, Telangana, INDIA Phone no: +91-9550306585 E-mail: pooja.gupthha@gmail. com

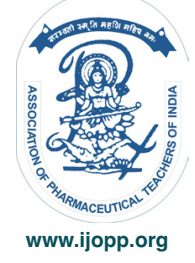


The labia or vaginal region is highly vascular, it consists of many tiny blood vessels. Hence chemicals are easily absorbed by this route. These slowly accumulate in our bodies and affects our reproductive health.

\section{Plastic chemicals}

Sanitary napkins are made of plastic chemicals like BPA and BPS complicate embryonic development and may cause organ damage. Pthalates, which gives a smooth finishing, dis regulate gene expression.

\section{Carcinogens}

The absorbent pads are not made of purely cotton, but also contain cellulose gel which causes cervical cancer. Dioxin, a byproduct of chlorine bleaching process are cumulative and the chemical may stay in the body about 20 years after exposure. It causes organ damage and affects immune system and also cause ovarian cancer. Rayon, a synthetic fiber and a byproduct of dioxin used to absorb wetness is carcinogenic.

\section{Pesticides and herbicides}

Sanitary napkins are made up of cotton, whereas many pesticides and herbicides are sprayed during the rearing of cotton causes harmful effects when they reach blood stream. Furan, an potentially dangerous chemical is present on cotton and will stay until its harvested. Pesticides and herbicides are linked to thyroid malfunction, infertility and other health problems.

\section{Toxic shock syndrome}

Prolonged use of sanitary napkins in a day causes an overgrowth of staphylococcus aureus in vagina which leads to Toxic Shock Syndrome. The toxins released by the bacteria causes a sudden drop in the blood pressure which is dangerous because the brain fails to get enough supply of blood. ${ }^{4,5}$

\section{METHOD OF STUDY}

In our survey we have collected opinions from various college students regarding their perception and usage of sanitary napkins. We started our work on November 2016 and completed by April 2017 during which we provided each student (around 500 students of age group 11-20 and 21-30) with a printed copy comprising of various queries regarding sanitary napkins. Finally, we had separated the data as per age groups comprising of 500 students out of which 308 students are of age group 11-20 and 189 students are of age group 21-30 and carried out our statistical studies. ${ }^{6,7}$
Table 1: Percentage of students experiencing discomfort, rashes or allergies.

\begin{tabular}{ccc}
\hline Opinion & Age: 11-20 & Age: 21-30 \\
\hline Regularly & $13.6 \%$ & $13.7 \%$ \\
Not at all & $40.9 \%$ & $36.5 \%$ \\
Rarely & $45.4 \%$ & $49.7 \%$
\end{tabular}

Table 2: Perception of students on price of the sanitary napkins

\begin{tabular}{ccc} 
Opinion & Age: $\mathbf{1 1 - 2 0}$ & Age: $\mathbf{2 1 - 3 0}$ \\
\hline Yes & $42.2 \%$ & $39.15 \%$ \\
No & $57.7 \%$ & $60.8 \%$
\end{tabular}

Table 3: Knowledge of students about chemicals that are used in preparation of sanitary napkins.

\begin{tabular}{ccc}
\hline Opinion & Age: $\mathbf{1 1 - 2 0}$ & Age: $\mathbf{2 1 - 3 0}$ \\
\hline Yes & $7.7 \%$ & $5.82 \%$ \\
Little knowledge & $33.1 \%$ & $38.6 \%$ \\
No idea & $59.09 \%$ & $55.5 \%$
\end{tabular}

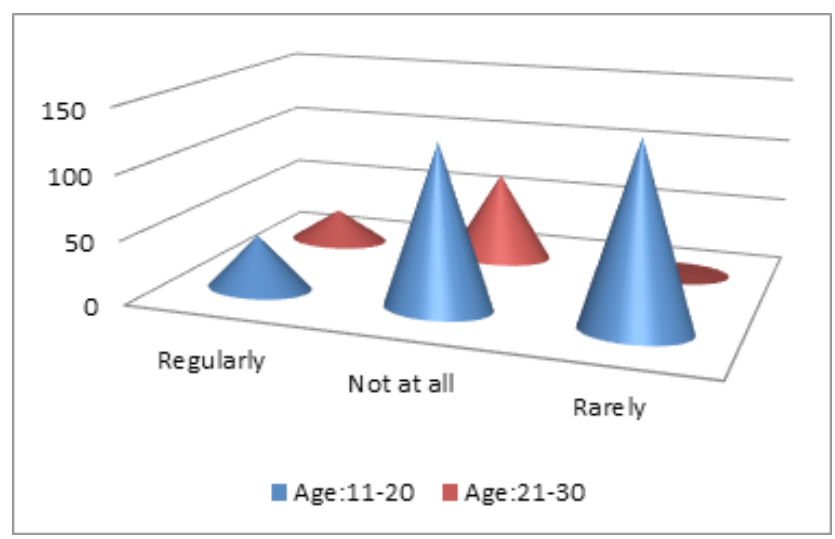

Figure 1: Graphical representation regarding discomfort and allergies.

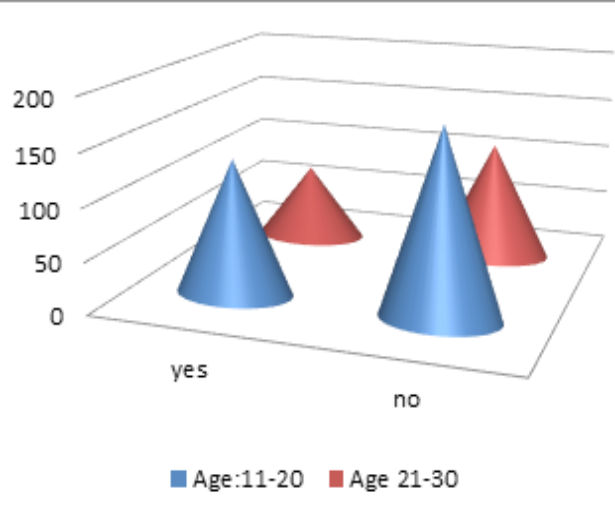

Figure 2: Graphical representation regarding Students perception on price.

Indian Journal of Pharmacy Practice, Vol 10, Issue 2, Apr-Jun, 2017 


\begin{tabular}{|c|c|c|}
\hline Time interval & Age: $11-20$ & Age: $21-30$ \\
\hline $3-4 \mathrm{hrs}$ & $27.5 \%$ & $25.3 \%$ \\
\hline 4-8 hrs & $48.05 \%$ & $45.5 \%$ \\
\hline $8-12$ hrs & $19.1 \%$ & $22.7 \%$ \\
\hline Above & $5.19 \%$ & $6.3 \%$ \\
\hline
\end{tabular}

Table 5: Factors that influence the selection of sanitary napkins

\begin{tabular}{ccc}
\hline Factors & Age: 11-20 & Age:21-30 \\
\hline Slim & $1.6 \%$ & $3.17 \%$ \\
Comfort & $35.06 \%$ & $25.3 \%$ \\
Size & $4.87 \%$ & $5.29 \%$ \\
Fragrance & $1.2 \%$ & $1.58 \%$ \\
Brand & $2.2 \%$ & $3.70 \%$ \\
Quality & $11.36 \%$ & $4.76 \%$ \\
Price & $4.87 \%$ & $6.37 \%$ \\
Package \& Design & $3.24 \%$ & $4.76 \%$ \\
Many of the mentioned reasons & $35.3 \%$ & $40.2 \%$ \\
\hline
\end{tabular}

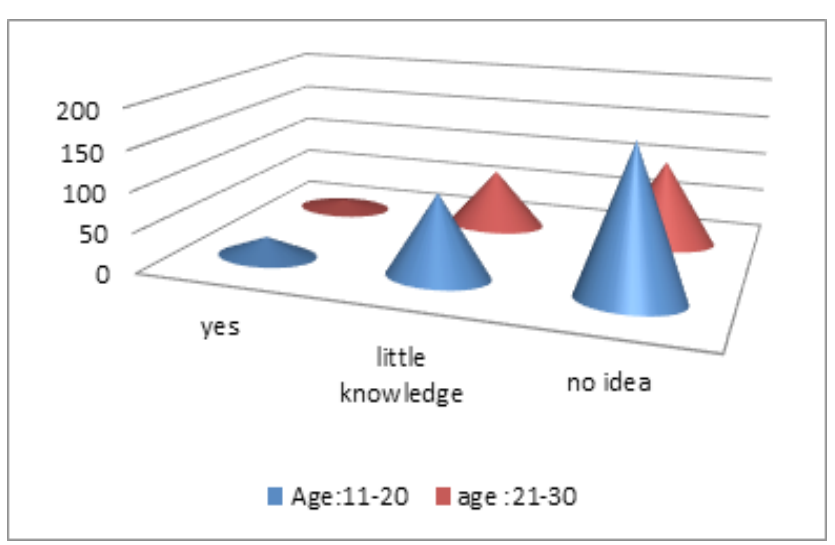

Figure 3: Graphical representation regarding knowledge on chemicals.

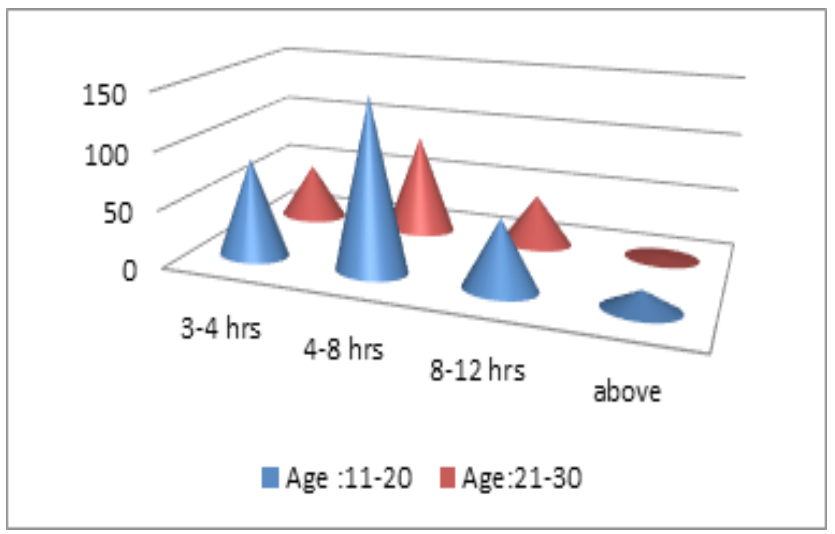

Figure 4: Graphical representation regarding time interval at which sanitary napkins are changed.

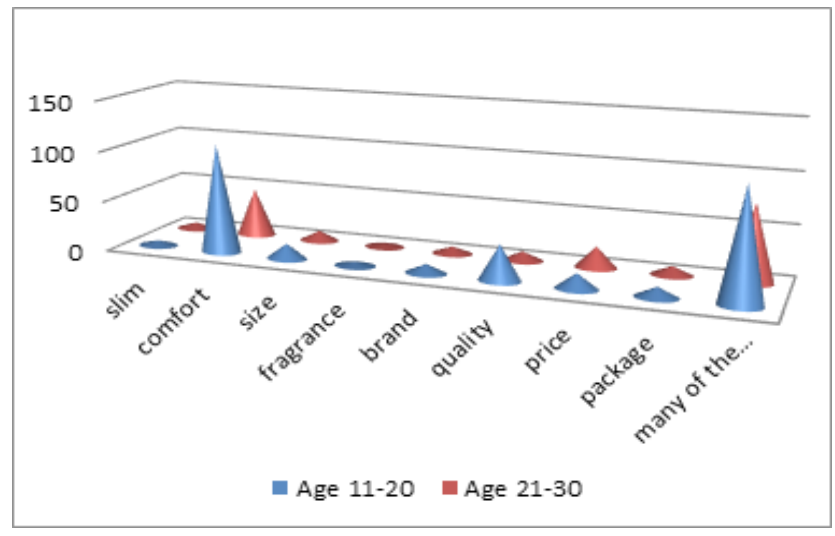

Figure 5: Graphical representation regarding factors influencing sanitary napkins selection.

\section{RESULTS}

A total of 500 students are provided with questionnaires regarding their perception on sanitary napkins. Later for carrying our studies we have divided them into two groups according to their age 11-20 and $21-30$.

\section{DISCUSSION}

In our study, we collected opinion from 500 students regarding their perception on sanitary napkins and we observed that;

In students of age group $11-20$ years $13.6 \%$ are experiencing discomfort with sanitary napkins regularly, $45.4 \%$ are experiencing discomfort rarely and $40.9 \%$ of students are not at all experiencing any discomfort (Table $1 \&$ Figure 1). $42.2 \%$ are satisfied with the price of sanitary napkins and $57.7 \%$ are not satisfied with the price (Table $2 \&$ Figure 2 ). $7.7 \%$ of students mentioned that they have idea about the chemicals used, 33.1\% students have little knowledge and $59.09 \%$ students have no idea about the chemicals used in sanitary napkins (Table 3 \& Figure 3). 27.5\% of students change their napkin at a time interval of 3-4 h, $48.05 \%$ of students for $4-8$ h, $19.1 \%$ of students for $8-12 \mathrm{~h}$ and $5.19 \%$ students above $12 \mathrm{~h}$ (Table 4 \& Figure 4$) .1 .6 \%$ of students prefer $\operatorname{sim}, 35.06 \%$ of students prefer comfort, $4.87 \%$ select based on size, $1.2 \%$ based on fragrance, $2.2 \%$ based on quality, $4.87 \%$ based on price, $3.24 \%$ based on package and design and $35.3 \%$ based on many of the mentioned reasons (Table $5 \&$ Figure 5).

Whereas in students of age group 21-30, 13.7\% are experiencing discomfort regularly, $49.7 \%$ are rarely experiencing discomfort and $36.5 \%$ of students are not at all experiencing any discomfort (Table $1 \&$ Figure 1). $39.15 \%$ of students are satisfied with the price (Table $2 \&$ Figure 2 ) and $60.8 \%$ of students are 
not satisfied with the price $5.82 \%$ of students have idea about chemicals, $38.6 \%$ of students have little knowledge and $55.5 \%$ of students are not at all having any idea (Table $3 \&$ Figure 3). 25.3\% of students change at an interval of $3-4 \mathrm{~h}, 45.5 \%$ of students for $4-8 \mathrm{~h}, 22.7 \%$ of students for $8-12 \mathrm{~h}$ and $6.3 \%$ of students above $12 \mathrm{~h}$ (Table 4 \& Figure 4). 3.17\% students prefer slim, $25.3 \%$ prefer comfort, $5.29 \%$ based on size, $1.58 \%$ based on fragrance, $3.70 \%$ based on brand, $4.76 \%$ based on quality, $6.37 \%$ based on price, $4.76 \%$ based on package and design and $40.2 \%$ based on many of the mentioned reasons (Table $5 \&$ Figure 5).

\section{CONCLUSION}

We have considered various factors like size, comfort, quality, chemicals, package, and price of sanitary napkins in our survey. Out of these we found out that apart from the problems arising from the usage of the sanitary napkins majority of the students from both the age groups are not satisfied with the price of the sanitary napkins and they are not aware regarding the chemicals used in the sanitary napkins.

\section{ACKNOWLEDGEMENT}

We are very thankful to the management and faculty of Browns College of Pharmacy for their sup- port in completion of our survey. We also convey our sincere regards to all Pharmacy and Engineering students who provided their valuable time for our work. Without their support it would not have been possible for us in completing our work in time.

\section{CONFLICT OF INTEREST}

The author declare no conflict of interest.

\section{ABBREVATIONS}

BPA: Bisphenol A; BPS: Bisphenol S.

\section{REFERENCES}

1. Freidenfelds $L$. Themodernperiod: Menstruation in twentieth-century. Baltimore: Johns Hopkins University Press; 2009.

2. Sinha, Kounteya." $70 \%$ can't afford sanitary napkins, reveals study", The Times of India, Jan 23, 2011, Retrieved April 8, 2013.

3. Vostral SL. Rely and Toxic Shock Syndrome: a technological health crisis. The Yale journal of biology and medicine. 2011;84(4):447.

4. Minor FW, Schwartz AM, Buckles LC, Wulkow EA, Marks MP, Fielding GH. The Migration of Liquids in Textile Assemblies: Part IV: Penetration of Fabrics by Liquids. Textile Research Journal. 1961;(6):525-39.

5. Des Jarlais DC, Lyles C, Crepaz N, TREND Group. Improving the reporting quality of nonrandomized evaluations of behavioral and public health interventions: the TREND statement. American journal of public health. 2004;94(3):361-6.

6. Alkire $\mathrm{S}$. The missing dimensions of poverty data: Introduction to the special issue. Oxford development studies. 2007;35(4):347-59.

7. Mohamed NG, Abidin NZ, Law KS, Abe M, Suzuki M, Muhamed AM, et al. The effect of wearing sanitary napkins of different thicknesses on physiological and psychological responses in Muslim females. Journal of physiological anthropology. 2014;33(1):28. 